\title{
var gene transcription and PfEMP1 expression in the rosetting and cytoadhesive Plasmodium falciparum clone FCR3S1.2
}

\author{
Letusa Albrecht ${ }^{1 \dagger}$, Kirsten Moll ${ }^{1 \dagger}$, Karin Blomqvist ${ }^{1}$, Johan Normark ${ }^{2}$, Qijun Chen ${ }^{1,3}$, Mats Wahlgren ${ }^{1 *}$
}

\begin{abstract}
Background: The pathogenicity of Plasmodium falciparum is in part due to the ability of the parasitized red blood cell (pRBC) to adhere to intra-vascular host cell receptors and serum-proteins. Binding of the PRBC is mediated by Plasmodium falciparum erythrocyte membrane protein 1 (PfEMP1), a large multi-variant molecule encoded by a family of $\approx 60$ var genes.

Methods: The study of var gene transcription in the parasite clone FCR3S1.2 was performed by semi-quantitative PCR and quantitative PCR (qPCR). The expression of the major PfEMP1 in FCR3S1.2 pRBC was analysed with polyclonal sera in rosette disruption assays and immunofluorecence.

Results: Transcripts from var1 (FCR3S1.2 var1; IT4var21) and other var genes were detected by semi-quantitative PCR but results from qPCR showed that one var gene transcript dominated over the others (FCR3S1.2var2; IT4var60). Antibodies raised in rats to the recombinant NTS-DBL1 $\alpha$ of var2 produced in E. coli completely and dosedependently disrupted rosettes ( $\approx 95 \%$ at a dilution of $1 / 5)$. The sera reacted with the Maurer's clefts in trophozoite stages (IFA) and to the infected erythrocyte surface (FACS) indicating that FCR3S1.2 var2 encodes the dominant PfEMP1 expressed in this parasite.

Conclusion: The major transcript in the rosetting model parasite FCR3S1.2 is FCR3S1.2 var2 (IT4var60). The results suggest that this gene encodes the PfEMP1-species responsible for the rosetting phenotype of this parasite. The activity of previously raised antibodies to the NTS-DBL1 $\alpha$ of FCR3S1.2 var1 is likely due to cross-reactivity with NTS-DBL1 $\alpha$ of the var2 encoded PfEMP1.
\end{abstract}

\section{Background}

The malaria parasite Plasmodium falciparum causes the death of around one million individuals annually, mainly small children. There are an estimated 300 million clinical cases annually in the world despite the fact that individuals are able to acquire immunity to the disease [1]. Protective immunity towards malaria develops, however, only after repeated exposure to the $P$. falciparum parasite and it is known to be in part dependent on antibodies towards the variable antigens present at the pRBC surface [2-9]. The best-characterized molecule of these surface antigens is the $P$. falciparum-infected

\footnotetext{
* Correspondence: mats.wahlgren@ki.se

+ Contributed equally

'Department of Microbiology, Tumor and Cell Biology (MTC), Karolinska Institutet, Box 280, SE-171 77 Stockholm, Sweden

Full list of author information is available at the end of the article
}

erythrocyte membrane protein 1 (PfEMP1). This protein family is encoded by a repertoire of around 60 var-genes per genome and the parasite can switch between different variants that are exported to the surface of the $\mathrm{pRBC}$ in order to evade the host's immune system [10]. In addition, the molecule PfEMP1 plays a central role in the parasite's ability to sequester in the microvasculature of the infected individual and to form rosettes between infected and uninfected RBC as well as giant-rosettes or auto-agglutinates $[3,11,12]$. Since PfEMP1 can bind to a variety of host-cell receptors the $\mathrm{pRBC}$ is able to avoid clearance in the spleen thus contributing substantially to the manifestations of severe malaria through excessive sequestration [13].

The N-terminal Duffy-binding like domain (DBL) $1 \alpha$ has the highest degree of sequence conservation among all domains of PfEMP1 $[14,15]$ and it is responsible

\section{() Biomed Central}


for binding to host receptors both on $\mathrm{RBC}$ and on endothelial cells [16-18]. This domain has, therefore, a central role in parasite sequestration in the microvasculature [18-20] and certain characteristics have been associated with severe disease [5,12,21-24]. DBL1 $\alpha$-domains of PfEMP1 of parasites of rosetting phenotypes have been described for the strains R29 [16], varO [25] and the clone FCR3S1.2 [17,26] (sequence alignment compare Figure 1A) which is the focus of this article.

var genes can be divided into five different classes according to their 5' upstream region [27] and it has been found, that rosetting parasites more frequently express var genes belonging to group $\mathrm{A}$, and group $\mathrm{A} / \mathrm{B}$ are more often transcribed in patients suffering from severe malaria [12,28-30]. The transcribed var gene repertoire in the rosetting parasite strain FCR3S1.2 was recently re-analysed and found that the dominant transcript is FCR3S1.2 var 2 (IT4var60) (Figure 1B) that also belongs to the group A-var genes. The original analysis and identification of the FCR3S1.2 $2_{\text {var } 1}$ as the dominant transcript [26] was carried out using degenerated primers modified after Su et al [31]. Now optimized RNA extraction and RT-PCR protocols were applied [12,32] using three sets of primer-pairs generated for the amplification of unknown DBL1 $\alpha$-sequences [12]. These transcripts were subsequently amplified using qPCR. With this

A

DBL1 $\alpha$ R29

DBL1 $\alpha$ VarO DBL1 $\alpha$ FCR3S1.2

DBL1 $\alpha$ R29

DBL $1 \alpha$ VarO DBL $1 \alpha$ FCR3S1.2

DBL1 $\alpha$ R29

$\mathrm{DBL} 1 \alpha$ VarO

DBL1 $\alpha$ FCR3S1.2

DBL1 $\alpha$ R29

$\mathrm{DBL} 1 \alpha$ VarO DBL $1 \alpha$ FCR3S1.2

DBL1 $\alpha$ R29 $\mathrm{DBL} 1 \alpha \operatorname{VarO}$ DBL1 $\alpha$ FCR3S1.2

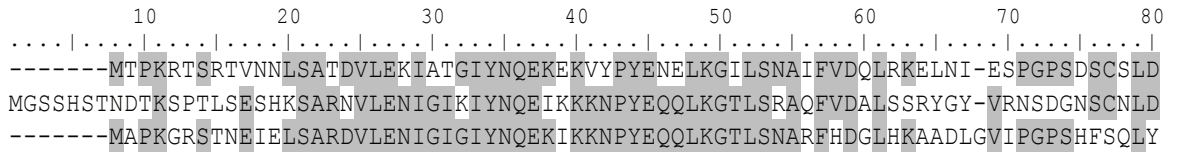

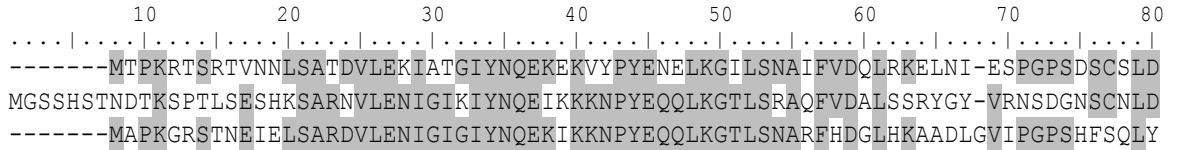

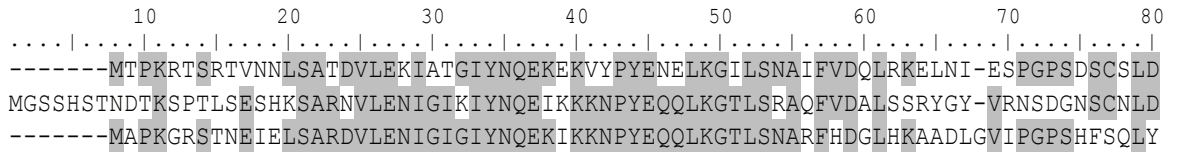

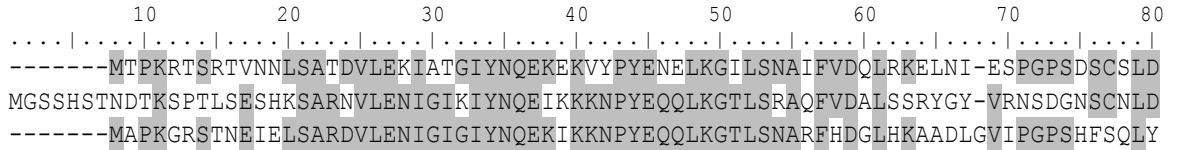

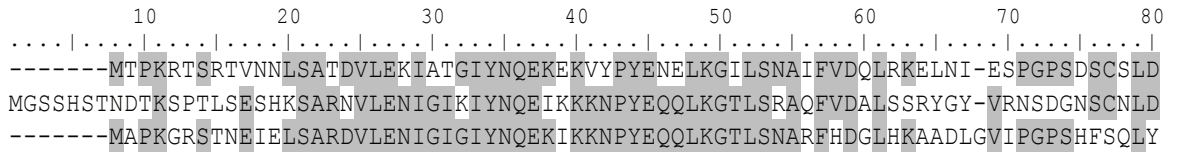

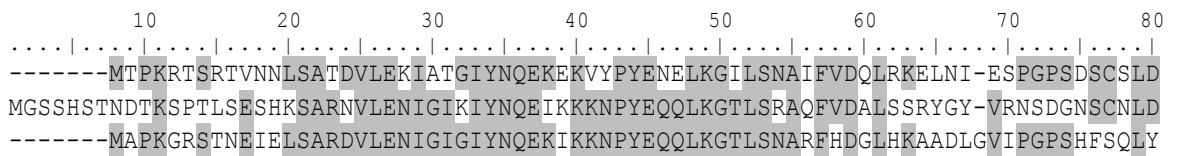

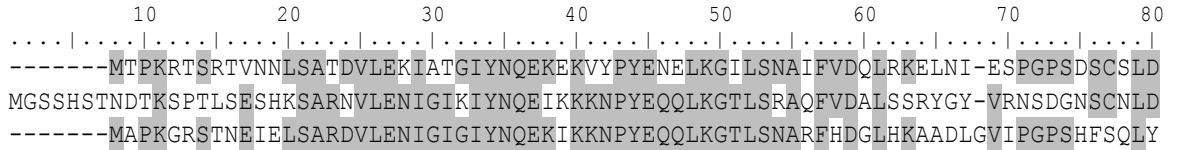

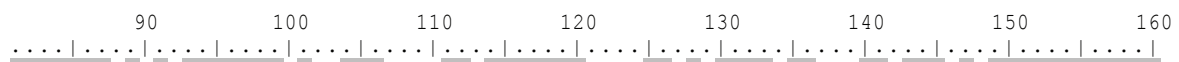
HKFHTNINTEYTEGRKPCYERNEKRESNEGEAKCGSDKIRDYGIKSAGGACAPFRRQNLCDRNLEYLINKNTNTTHDLLG HLFHTN IKTGYNEGRKPCYGREQNRFDENAEAYCNSDK IRGNENNSNGTACAPPRRRH ICDQNLEFLDNKNTNTTHDLLG YKKHTNNTKYYKDDRHPCHGRQGKRFDEGQKEECGNDKI I GNSDKYG--SCAPPRRRH ICDQNLEFLDNNHTDTI HDVLG 170
$\ldots \ldots|\ldots| \ldots|\ldots| \ldots|\ldots| \ldots|\ldots| \ldots|\ldots| \ldots|\ldots| \ldots|\ldots| \ldots|\ldots| \ldots|\ldots| \ldots|\ldots| \ldots \mid$ NVLVTAKYEGNYIVNDHPDKNSNGNKSGICTSLARSFADI GDIVRGRDMFLPNKDDKVQKGLQVVFKKIYKSLTPEARKH NVLVTAKYEGES IVNDHPDKKNNGNKSGICTSLARSFADIGDIVRGRDMFKPNDKDAVRHGLKVVFKKIYDKLSPKVQEH $\begin{array}{rrrrrrr}250 & 260 & 270 & 280 & 290 & 300 & 310\end{array}$ YAHDDGSGNYYKLREDWWAINRKEVWKAITCRAPNEANFERNISGNMKAFTSQGYCGHSETNVPTNLDYVPQFLRWFDEW YAHGDGSGNYSKLREDWWTINREQIWKALTCSAPYYADYFRKGSDGTLHFSSHGKCGHNEGAPPTYLDYVPQFLRWFEEW YKDVDGSGNYYKLREDWWTANRDQVWKAITYKAPQDANYFRNVSGTTMAFTSAGKCRHNDNSVPTNLDYVPQFLRWYDEW

340 350 360 370 380 390 400 $\ldots \ldots|\ldots| \ldots|\ldots| \ldots|\ldots| \ldots|\ldots| \ldots|\ldots| \ldots|\ldots| \ldots|\ldots| \ldots|\ldots| \ldots|\ldots| \ldots \mid$ SEEFCRIKKIKIDKVKKECRDEQN---KKYCSGDGHDCTQTNLSHNQI FVDLDCPRCQDQCIKYNEWIVKKLEEFYKQNL ADDFCRIRNHKLQKVKDTCQGYNNSGYRIYCSGDGEDCTNILKQNFNIVSDFFCPSCKTECTNYKKWINKKQGE FNKQKK

DBL1 $\alpha$ R29

DBL1 $\alpha$ VarO

DBL $1 \alpha$ FCR3S1.2

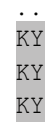

B

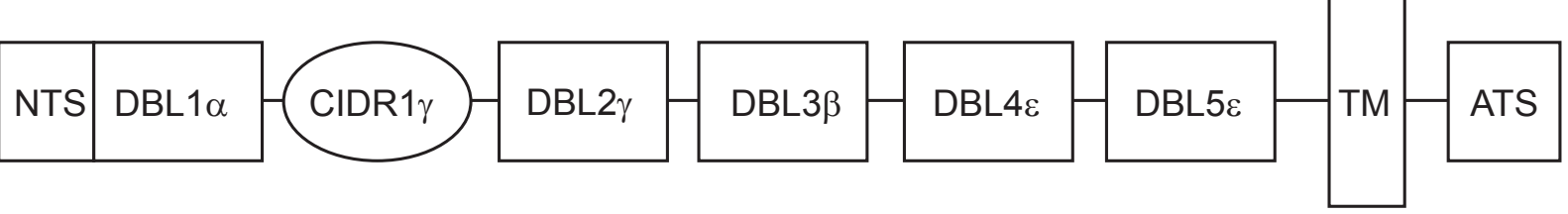

Figure 1 Structure and sequence comparison of the FCR3S1.2 var2 gene A: Alignment of the protein sequence of the rosette associated DBL1 $\alpha$ domains of the parasite strains FCR3S1.2, R29 and Palo Alto varO. B: Schematical presentation of the FCR3S1.2var2 gene structure. 
approach, a different var gene (FCR3S1.2 $2_{\text {var } 2}$ ) was found to be the dominantly transcribed in FCR3S1.2. Sera raised against the NTS-DBL1 $\alpha$-domain of FCR3S1.2 $2_{\text {var } 2}$ showed a PfEMP1-specific immunofluorescence pattern, stained the FCR3S1.2 pRBC surface in FACS and disrupted the rosettes of this parasite clone.

\section{Methods}

\section{Parasite cultures}

The P. falciparum laboratory clone FCR3S1.2 [33] was cultivated as described in blood group O RBC [34]. The phenotype of FCR3S1.2 was maintained by weekly enrichment over a Ficoll-gradient [34]. FCR3S1.2 pRBC of different generations after cloning were used in the experiments. Transcription levels were measured in different cultures of FCR3S1.2 including: A) parasites 18 generations after micromanipulation cloning (FCR3S1.2$18 \mathrm{G}$; $85 \%$ rosetting) [33]; B) parasites $\geq 100$ generations after cloning (FCR3S1.2-100 G, 85\% rosetting) and C) parasites after 28 generations of additional growth of the parasites of (B) (FCR3S1.2-100 G) in the absence of Ficoll enrichment (FCR3S1.2 128 G, 78\% rosetting). The pRBC of FCR3S1.2 avidly bind to a number human cellular receptors and serum-proteins (Table 1).

\section{RNA extraction, amplification of var transcript by RT-PCR and semi-quantitative PCR}

RNA was extracted from FCR3S1.2 early trophozoites (18-24 h p.i.) at $\geq 100$ generations after cloning with the QiagenRNeasy kit with minor modifications, followed by treatment with TURBO DNAse in order to remove any remaining DNA (Ambion, Austin TX, USA) as previously described [32]. Reverse transcription was carried out using superscript III (Invitrogen, Carlsbad, CA, USA) with random hexamers and oligo(dT)12-18 (300 ng/ml and $25 \mathrm{ng} / \mathrm{ml}$ respectively) at $25^{\circ} \mathrm{C}$ for $10 \mathrm{~min}$ and $50^{\circ} \mathrm{C}$ for $120 \mathrm{~min}$ followed by $70^{\circ} \mathrm{C}$ for $15 \mathrm{~min}$. A control reaction without reverse transcriptase (RT-) was performed for each cDNA synthesis reaction. cDNA was used as template for PCR with the degenerated primers nDBLf (TKGCAGCMAAWTAYGARGX), nDBLr (KTCCACCAATCTTCYCT), $\alpha$-AF (GCACGMAGTTTTGC) and $\alpha$-BR (GCCCATTCSTCGAACCA). AccuTaq LA DNA polymerase mix was used (Sigma, Saint Louis, MA, USA) and the cycling conditions were $3 \mathrm{~min}$ denaturation followed by 35 cycles of $30 \mathrm{sec}$ at $45^{\circ} \mathrm{C}, 45 \mathrm{sec}$ at $60^{\circ} \mathrm{C}$, $15 \mathrm{sec}$ at $94^{\circ} \mathrm{C}$ and finally $7 \mathrm{~min}$ at $72^{\circ} \mathrm{C}[12,32]$. PCR products were cloned using the TOPO TA cloning kit (Invitrogen). Forty-eight clones for each primer pair were subsequently sequenced using the MegaBace system.

\section{Quantitative PCR}

In order to quantify the transcripts identified by semiquantitative PCR in FCR3S1.2 quantitative PCR (qPCR)
Table 1 Summary of adhesive characteristics of pRBC of the $P$. falciparum clone FCR3S1.2

\begin{tabular}{|c|c|}
\hline in vivo & \\
\hline Intravascular sequestration in Sprague Dawley rats ${ }^{a}$ & + \\
\hline Intravascular sequestration in Macaca fascicularis ${ }^{a}$ & + \\
\hline in vitro & \\
\hline Rosetting (\% rosetting $\mathrm{pRBC})^{\mathrm{b}}$ & $80-90 \%$ \\
\hline Giant-rosetting/auto-agglutination ${ }^{b}$ & + \\
\hline Soluble heparin ${ }^{c}$ & $90 \%$ \\
\hline Blood Group $A^{c}$ & $90 \%$ \\
\hline Ig-binding anti-lg ${ }^{c}$ & $96 \%$ \\
\hline Ig-binding anti-Ig $M^{c}$ & $90 \%$ \\
\hline Ig-binding anti-lgG ${ }^{c}$ & $12-20 \%$ \\
\hline HUVEC ${ }^{d}$ & $1,200-1,600$ \\
\hline Melanoma cells ${ }^{d}$ & $400-500$ \\
\hline $\mathrm{CHO}-\mathrm{CD} 36^{\mathrm{d}}$ & $200-300$ \\
\hline $\mathrm{CHO}-\mathrm{ICAM}^{\mathrm{d}}$ & $40 \pm 12$ \\
\hline $\mathrm{CHO}_{\text {cells }}{ }^{\mathrm{d}}$ & $6 \pm 3$ \\
\hline L-cells (PECAM-1/CD31) ${ }^{\mathrm{d}}$ & $390 \pm 28$ \\
\hline$L-$ cells $^{d}$ & 5 \\
\hline sPECAM-1/CD31 ${ }^{d}$ & $183 \pm 31$ \\
\hline $\mathrm{TSP}^{\mathrm{e}}$ & - \\
\hline $\mathrm{CSA}^{\mathrm{e}}$ & - \\
\hline Placenta ${ }^{f}$ & 0 \\
\hline
\end{tabular}

a) Rats or macaques were administrated with ${ }^{99} \mathrm{~m}_{\text {Technetium-labeled } \mathrm{pRBC} \text { of }}$ the FCR3S1.2 clone by injection into the tail vein (rats) or Vena saphena magna (macaques). The animals were left for 60 min after which sequestration was measured in a triple headed-gamma camera $[20,44]$. b) Rosetting rates are expressed as the range of percent rosetting trophozoite-pRBC [33].

c) Percentage of late stage $\mathrm{PRBC}$ showing surface fluorescence when incubated with antibodies to human non-immune $\lg$, IgM or $\operatorname{lgG}$, or heparin, or the blood group $\mathrm{ABO}$ antigens [33].

d) Number of pRBC bound per 100 cells $[17,33]$.

e) Number of late stage pRBCs bound to thrombospondin-coated plastic (50 $\mathrm{mg} / \mathrm{ml}$ ).

f) Number of IEs bound to $1 \mathrm{~mm}^{2}$ of placental tissue.

was performed as previously described [32]. Oligonucleotides were designed based on DBL1 $\alpha$ sequences obtained from the semi-quantitive PCR, using Primer Express (version 3.0, Applied 215 Biosystems, Foster City, CA, USA) and Netprimer (Premier Biosoft, 216 Palo Alto, CA, USA) (Additional file 1).

The evaluation of var transcripts was done for $\mathrm{pRBC}$ of A) parasites 18 generations after cloning (FCR3S1.2$18 \mathrm{G}, 85 \%$ rosetting), B) parasites $\geq 100$ generations after cloning (FCR3S1.2-100 G, 85\% rosetting) and C) with pRBC of FCR3S1.2 grown for an additional 28 generations without any Ficoll enrichment (FCR3S1.2-128 G, $78 \%$ rosetting). After RNA extraction and DNAse treatment (as described above) the RNA was analysed using 2100 Bioanalyzer (Agilent Tecnology). The RNA was further processed when the RNA integrity (RIN) was above 5 [35]. qPCR reactions were prepared in quadruplicates containing Power SYBR Green master mix 
(Applied Biosystems) in $10 \mu \mathrm{l}$ volumes at a $300 \mathrm{nM}$ concentration for each primer. Quantitative amplifications were performed through 45 cycles $\left(95^{\circ} \mathrm{C}\right.$ for $15 \mathrm{~s}$ and $60^{\circ} \mathrm{C}$ for $1 \mathrm{~min}$ ) in an ABI 7900 qPCR system (Applied Biosystems). Seryl-tRNA-synthetase was used as an endogenous control for relative quantification. qPCR results were analysed as earlier described [32].

\section{Production of NTS-DBL $1 \alpha_{\text {var2 }}$ protein in E. coli and polyclonal NTS-DBL1 $\alpha_{\text {var2 }}$ sera}

The NTS-DBL1 $\alpha_{\text {var2 }}$ domain was amplified from genomic DNA of the parasite clone FCR3S1.2 (forward primer: CCA TGG CAC CAA AGG GTA GAA; reverse primer: AGA TCT GTA TTT TTTTTT TTG TTT ATT AAA TTC) and cloned into the pQE60 vector (vector $p Q E$, Qiagen, USA), expression and purification of histagged NTS-DBL1 $\alpha_{\text {var2 }}$ domain was carried out as described [36]. Three male Sprague Dawley rats (3 months old) received four immunizations with recombinant NTS-DBL1 $\alpha_{\text {var2 }}$ protein on days $0,30,60$ and 90 (50 $\mu \mathrm{g} / \mathrm{rat}$ ) emulsified in Freund's complete (first immunization) or incomplete adjuvant (second to fourth immunization). Sera were collected four weeks after the last immunization.

\section{Rosette disruption assay}

The capacity of the immune sera raised in rats against recombinant NTS-DBL1 $\alpha_{\text {var2 } 2}$ to disrupt rosettes of the FCR3S1.2 clone in blood group O RBC (dilutions: 1:5, $1: 10,1: 20,1: 40,1: 80)$ was assayed as described [17]. As a positive control a purified IgG fraction of a Malawian hyper-immune sera pool was used. Malaria naïve Swedish sera and pre-immune rat sera were used as controls.

\section{Immunofluorescence assays with anti NTS-DBL1 $\alpha_{\text {var2 }}$ sera}

Air-dried monolayers of trophozoite-pRBC of the FCR3S1.2 clone were obtained as described previously [37]. The monolayers were incubated $60 \mathrm{~min}$ with polyclonal NTS-DBL1 $\alpha_{\text {var2 } 2}$ sera diluted in PBS (1:50), washed three times in PBS, and incubated 60 min with an ALEXA488- conjugated goat anti-rat antibody (Molecular Probes, Invitrogen). All incubations were carried out at RT in a humid chamber. Preparations were mounted with an anti-fading solution consisting of $20 \%$ DABCO (Sigma) in glycerol, and analysed with $10 \times$ ocular and a 100x oil immersion lens in a Nikon Eclipse 80i microscope.

\section{Analysis of surface recognition by flow cytometry}

Trophozoite $\mathrm{pRBCs}$ of $\approx 24-30$ p.i. were incubated in a dilution of 1:20 with the polyclonal NTS-DBL1 $\alpha_{\text {var2 }}$ rat sera for $30 \mathrm{~min}$ at $\mathrm{RT}$. The $\mathrm{pRBC}$ were washed twice with PBS/FCS after incubation with the primary antibody followed by a $30 \mathrm{~min}$ incubation with a goat anti-rat IgG antibody coupled to ALEXA488 (dilution $1: 100)$. For nuclear staining ethidium bromide was added at final concentration $2.5 \mu \mathrm{g} / \mathrm{ml}$ and resuspended in PBS with $2 \%$ FCS. The cell acquisition was done using flow cytometry (FACSCalibur, BD Bioscience, http://www.bd.com) where 5000 pRBC were counted. The analysis was performed using the software Cell Quest Pro (BD Bioscience).

\section{Results}

Amplification of the transcribed var gene in FCR3S1.2 by RT-PCR

The reverse transcriptase-PCR (RT-PCR) amplification was carried out with three sets of degenerate primer pairs $(\alpha-\mathrm{AF} / \alpha-\mathrm{BR}, \mathrm{nDBLf} / \mathrm{nDBLr}, \mathrm{nDBLf} / \alpha-\mathrm{BR})$ and sequencing generated a total of 111 sequence reads after post quality control. These were divided into contigs and analysed as previously described [12,32]. FCR3S1.2 expressed a range of var genes, not necessarily fulllength transcripts; in total 40 var genes were amplified, where five of those sequences were present in $60 \%$ of the total reads (Figure 2). A gene referred to as var2 (IT4var60) was the most dominant var gene transcribed with $28 \%$ of the reads. Low transcript levels of the var1 gene were also detected ( $6.3 \%$ of the reads). The distribution of transcribed var genes is shown in Figure 2.

\section{Amplification of the transcribed var gene in FCR3S1.2 by qPCR}

After the identification of var genes transcripts by semiquantitative PCR a depth analysis was performed using qPCR. The five most frequent var transcripts but also

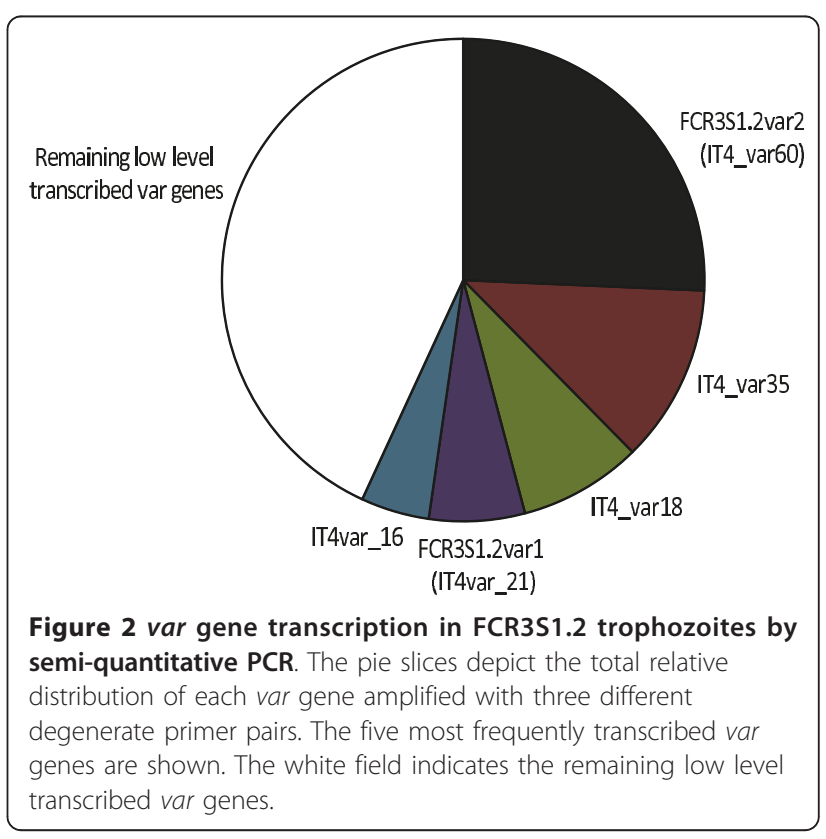


nine minor transcripts identified in the semi-quantitative PCR and two conserved var transcripts (var2csa and var3) were analysed by GPCR. The predominant var gene identified here was identical with the one found by semi-quantitative PCR, here named FCR3S1.2 2 ar 2 (Figure 3). Independent of the number of generations after cloning (18 or $\geq 100$ generations) or minor differences in the rosetting rate ( $85 \%$ versus $78 \%$ ), the results showed the same dominant var transcript. This transcript has $100 \%$ identity with the DBL1 $\alpha$ domain of IT4var60 [15]. The semi-quantitative PCR and qPCR results, therefore, suggest that FCR3S1.2 $2_{\text {var } 2}$ is the most dominant var transcript in FCR3S1.2. Minor transcripts, such as IT4var21 (var1) and IT4var35 were also found employing qPCR, in particular in the earlier generations of the FCR3S1.2 parasite clone (FCR3S1.2 18 G).

\section{Analysis of the expressed PfEMP1 in FCR3S1.2}

The expression of PfEMP1 in the parasite clone FCR3S1.2 was analysed using sera raised in rats against the Escherichia coli-produced, his-tagged NTS-DBL1 $\alpha$ var2. Indirect immunofluorescence was carried out on

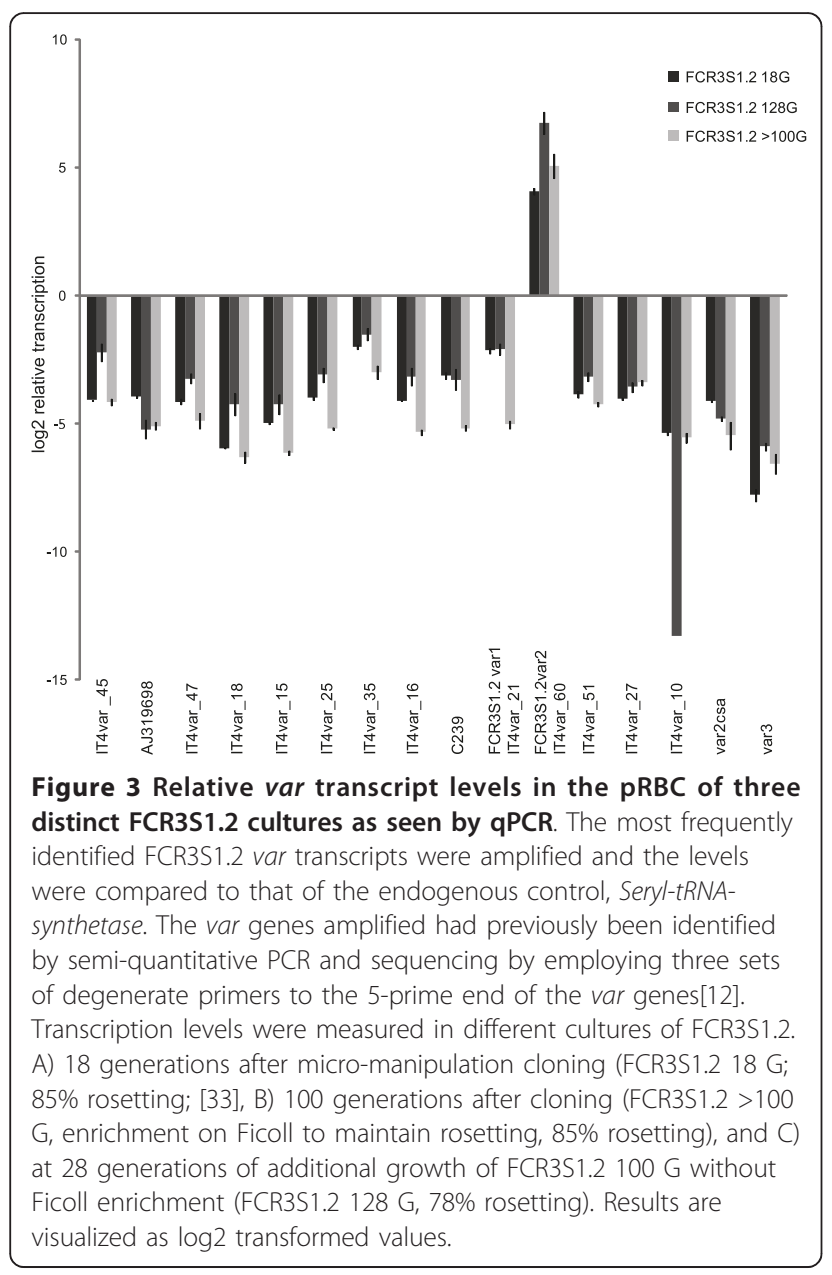

air-dried monolayers of pRBC harbouring trophozoite stages of 24-30 h p.i. The observed pattern in the pRBC showed staining of multiple vesicular structures typical for trafficking of PfEMP1 in Maurer's clefts (Figure 4). Pre-immune sera from the same animals did not show any staining of the pRBC-monolayers. In addition, staining of live pRBC with the anti-NTS-DBL1 $\alpha_{\text {var2 }}$ was carried out using flow-cytometry and IFA of live pRBC. Around $75 \%$ of the pRBC showed surface reactivity with the anti-NTS-DBL1 $\alpha_{\text {var2 }}$ sera (Figure 5). The number of pRBC showing surface reactivity correlated to the rate of FCR3S1.2 pRBC involved in rosetting/auto-agglutination in each experiment. Pre-immune sera of the immunized rats did not result in any surface reactivity with the $\mathrm{pRBC}$.

\section{Functional analysis of anti-NTS-DBL $1 \alpha_{\text {var2 }}$ antibodies}

Functional analysis of the anti-NTS-DBL $1 \alpha_{\text {var2 }}$ antibodies was carried out by analyzing their capacity to disrupt rosettes and auto-agglutinates of the clone FCR3S1.2. The sera were assayed in duplicates in dilution series from 1:5 to $1: 80$ and showed a strong and dose-dependent ability to disrupt rosettes as compared to a non-treated control (relative rosetting rates: $7.2 \%$ for dilution $1: 5,17.1 \%$ for $1: 10,32.1 \%$ for $1: 20,49.4 \%$ for $1: 40,73.5 \%$ for $1: 80$ and $89.3 \%$ for pre immune serum; Figure 6). The effect of the anti-NTS-DBL1 $\alpha_{\text {var2 }}$ serum on rosetting in FCR3S1.2 was higher than that of a hyper-immune pool from Malawi, which in a dilution of $1: 10$ gave a relative rosetting rate of $56.9 \%$ as compared to $10.1 \%$ for the anti-NTS-DBL $1 \alpha_{\text {var } 2}$ serum. Preimmune sera from the same animals did not disrupt rosettes and auto-agglutinates.

\section{Discussion}

Here, the FCR3S1.2 var2 gene coding for the PfEMP1 that mediates rosetting in the parasite strain FCR3S1.2 was identified. Furthermore, it was shown that antibodies towards the NTS-DBL1 $\alpha$-domain of FCR3S1.2 var2
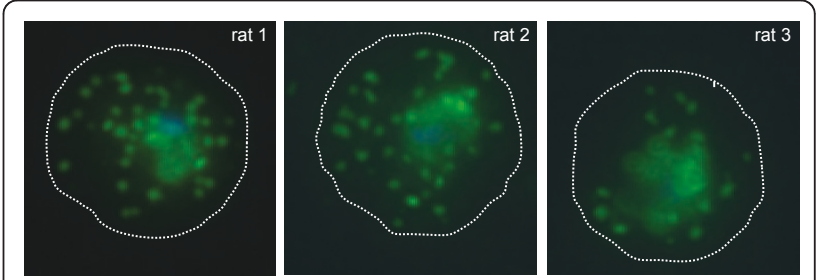

Figure 4 PfEMP1 of FCR3S1.2 var2. Indirect staining of $\mathrm{pRBC}$ of FCR3S1.2 with anti-NTS-DBL $1 \alpha_{\text {var2 }}$ sera from three individual rats: Maurer's-cleft pattern is observed when staining air-dried monolayers of pRBC with anti-NTS-DBL1 $\alpha_{\text {var2 }}$ sera (green). Parasite nuclei were counterstained with Hoechst (blue). Pre-immune sera did not show any reactivity. 

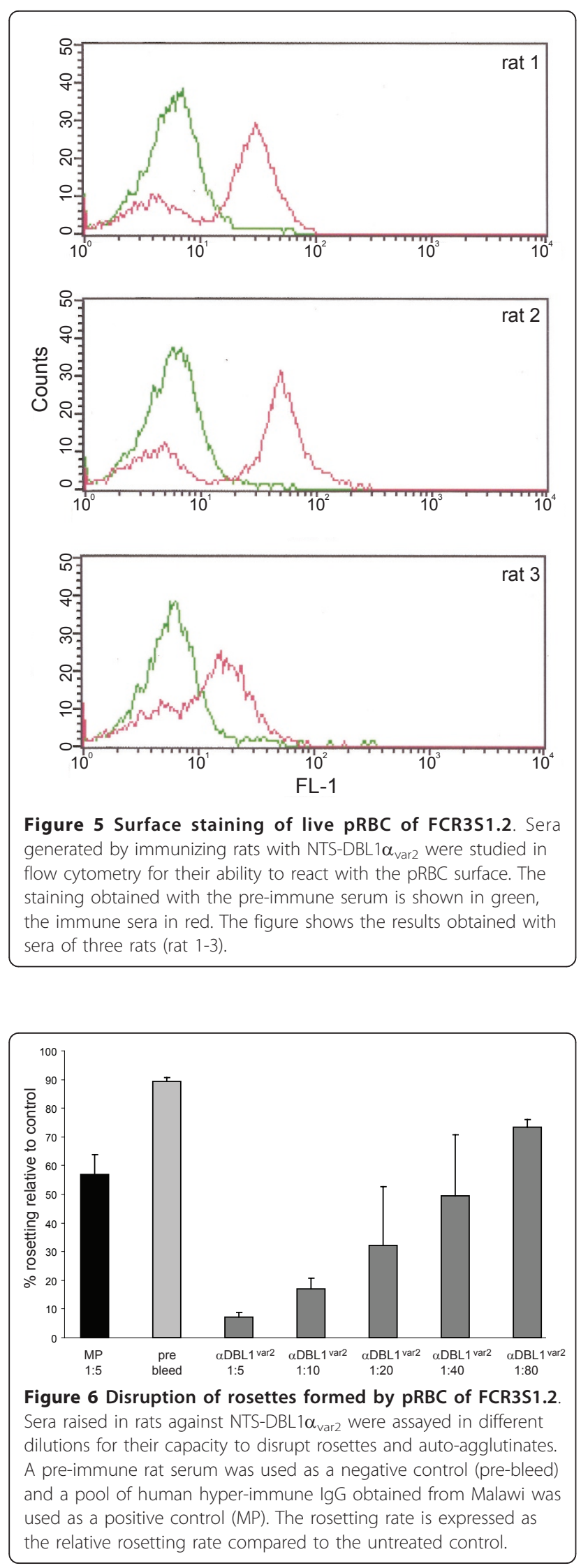

recognize the surface of the $\mathrm{pRBC}$ and are able to disrupt rosettes of FCR3S1.2 parasite.

New tools have been developed for the study of molecular processes and their quality has improved over the last 15 years. Further, the accessibility of complete $P$. falciparum genomes $[15,38]$ and a number of studies analysing variable sequences has facilitated the study of polymorphic genes in this pathogen [12]. Sequence information has helped in the development of ways to analyse the variable genes. In 1998 when the dominant var transcript in the rosetting parasite FCR3S1.2 was first identified [26], only few var sequences were available and the tools for studying these genes were limited. At that time, the single cell PCR and Northern blot techniques were used to recognize the dominant transcript in FCR3S1.2 leading to the identification of the gene FCR3S1.2 var1 [26]. In contrast, in the present study, two different primer pairs in three different combinations in RT-PCR were applied [12,32]. Thereafter and based on the results from the RT-PCR, primers to the five most dominant var genes as well as to two conserved var genes (var3 and var2CSA) were designed. In addition, nine var genes that were found as minor transcript (less than 4 sequence-reads) were included. These primers were subsequently used to analyse the var gene transcription by quantitative PCR. Using this more indepth approach we found a different FCR3S1.2 var gene (var2) to be predominantly transcribed in the same parasite.

In order to investigate whether a var gene switch had occurred during growth of the parasite over the years, parasites frozen immediately after the cloning of the FCR3S1.2 (18 generations) were compared to more than 100 generations after cloning. In both cases, the same predominant var transcript was found, suggesting that the var gene FCR3S1.2 var2 (IT4var60) was already the major transcript at the time of cloning. The primer pair used in 1998 for the identification of FCR3S1.2 $2_{\text {var } 1}$ transcript in FCR3S1.2 includes several degenerated nucleotides $(8 / 20$ in the forward primer and $7 / 20$ in the reverse primer) (Figure 7). This could be the reason why var 1 was identified, although this primer pair shows no bias [26].

Functional assays with polyclonal antibodies towards the NTS-DBL1 $\alpha_{\text {var2 }}$ show that these antibodies are able to disrupt almost $100 \%$ of the rosettes in the homologous parasite whereas antibodies against the NTSDBL1 $\alpha_{\text {var1 }}$ disrupt rosettes to a lower extent in the same parasite (Additional file 2) $[19,39]$. Cross-reactivity of NTS-DBL1 $\alpha_{\text {var1 }}$ antibodies to heterologous NTSDBL1 $\alpha$-domains such as the one of the R29 parasite strain has also previously been reported by this group [39]. In addition, the ability of antibodies to disrupt rosettes and impair sequestration in the rat has been observed in several other studies suggesting that anti- 


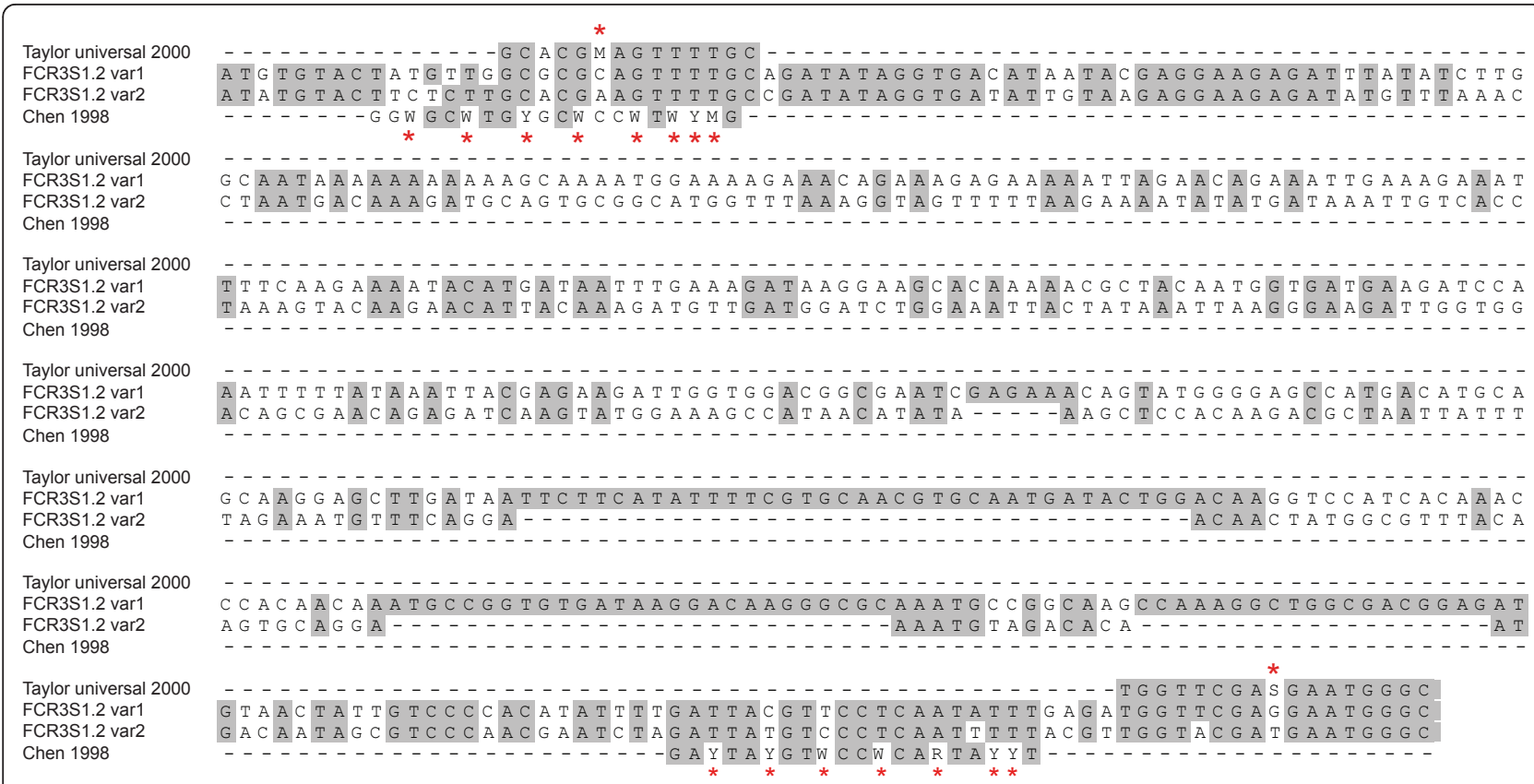

Figure 7 Sequence alignment of the DBL1 $\alpha$-domain sequence and PCR-primers used Comparison of the DBL1 $\alpha$ - and oligonucleotidesequences to depict mismatches of the primers used in the original identification of the dominant var gene in the FCR3S1.2 parasite: Aligned are the "Taylor universal 2000" [43] oligonucletides, the DBL1 $\alpha$-sequence of var1, var2 of FCR3S1.2 as well as the originally used oligonucleotides named "Chen 1998" [26]. The stars indicate degenerate nucleotides in the primer pairs.

PfEMP1 antibodies may cross-react in-between different parasites $[4,5]$.

Depending on the 5 ' upstream region, var genes can be divided into 5 different subgroups, the FCR3S1.2 $2_{\text {var } 2}$ also known as IT4var60 gene identified here belongs to the group A var genes [15]. FCR3S1.2 var2 lacks two cysteines in the DBL1 $\alpha$ domain as compared to FCR3S1.2 var1 and this characteristic has previously been associated with a rosetting phenotype and/or severe malaria $[12,25,40,41]$. The FCR3S1.2 $2_{\text {var } 2} /$ IT4var60 gene was also found associated with the rosetting phenotype in a previous study [42]. Taken together this suggests that DBL $1 \alpha_{\text {var2 }}$ of FCR3S1.2 has characteristics that fit well with the rosetting phenotype of this parasite. Still, the results do not entirely discard the possibility that a small population of the FCR3S1.2 parasites transcribes the previously identified FCR3S1.2 $2_{\text {var } 1}$. The rosetting rate when enriched on a Ficoll gradient, is about $85-90 \%$, but never reaches $100 \%$, a fact which may indicate that a small subpopulation of the parasites express PfEMP1 variants other than the PfEMP1 encoded by var2.

\section{Conclusions}

The results presented here show that the FCR3S1.2 parasite clone expresses one dominant var gene transcript, FCR3S1.2 var2 (IT4var60), which belongs to the group A var genes. The encoded PfEMP $1_{\text {var2 }}$ carries a two-cysteine-signature associated with rosetting and antibodies to the protein avidly stain the pRBC suggesting that FCR3S1.2 var2 is the dominant var gene expressed in this parasite.

\section{Additional material}

Additional file 1: Oligonucleotides used for qPCR experiments. The data provided show the oligonucleotides used for QPCR are described below or previously described by Blomqvist et al [32].

Additional file 2: Rosette disruption in FCR3S1.2 pRBC. Rosette disruption of FCR3S1.2 pRBC with sera raised against the DBL1 $\alpha$-domain of FCR3S1.2 var1, respectively FCR3S1.2 var2

\section{Abbreviations}

DBL: Duffy-binding like; PfEMP1: Plasmodium falciparum erythrocyte membrane protein 1; pRBC: parasitized red blood cell; qPCR: quantitative PCR

\section{Acknowledgements}

We thank the staff at the animal laboratory of the Swedish Institute for Infectious Disease Control (SMI) for animal husbandry and assistance with immunization.

\section{Author details}

'Department of Microbiology, Tumor and Cell Biology (MTC), Karolinska Institutet, Box 280, SE-171 77 Stockholm, Sweden. ${ }^{2}$ Department of Molecular Biology, Umeå University, Umeå SE-90187, Sweden. ${ }^{3}$ Chinese Academy of Medical Sciences, Beijing, China.

\section{Authors' contributions}

LA carried out GPCR experiments and analysis. KM generated recombinant protein, sera and carried out IFA and rosette disruption experiments. KB and 
JN carried out semi-quantitative PCR and designed QPCR primers. LA, KM $\mathrm{KB}, \mathrm{MW}$ and QC drafted and wrote the manuscript. All authors have read and approved the final manuscript.

\section{Competing interests}

The authors declare that they have no competing interests.

Received: 18 November 2010 Accepted: 25 January 2011

Published: 25 January 2011

\section{References}

1. WHO: World Malaria Report 20082008.

2. Hommel M, David PH, Oligino LD: Surface alterations of erythrocytes in Plasmodium falciparum malaria. Antigenic variation, antigenic diversity, and the role of the spleen. J Exp Med 1983, 157:1137-1148.

3. David PH, Hommel M, Miller LH, Udeinya IJ, Oligino LD: Parasite sequestration in Plasmodium falciparum malaria: spleen and antibody modulation of cytoadherence of infected erythrocytes. Proc Natl Acad Sci USA 1983, 80:5075-5079.

4. Marsh K, Howard RJ: Antigens induced on erythrocytes by $P$. falciparum: expression of diverse and conserved determinants. Science 1986, 231:150-153.

5. Carlson J, Helmby H, Hill AV, Brewster D, Greenwood BM, Wahlgren M: Human cerebral malaria: association with erythrocyte rosetting and lack of anti-rosetting antibodies. Lancet 1990, 336:1457-1460.

6. Bull PC, Lowe BS, Kortok M, Marsh K: Antibody recognition of Plasmodium falciparum erythrocyte surface antigens in Kenya: evidence for rare and prevalent variants. Infect Immun 1999, 67:733-739.

7. Bull PC, Lowe BS, Kortok M, Molyneux CS, Newbold CI, Marsh K: Parasite antigens on the infected red cell surface are targets for naturally acquired immunity to malaria. Nat Med 1998, 4:358-360.

8. Ofori MF, Dodoo D, Staalsoe T, Kurtzhals JA, Koram K, Theander TG, Akanmori BD, Hviid L: Malaria-induced acquisition of antibodies to Plasmodium falciparum variant surface antigens.[see comment]. Infect Immun 2002, 70:2982-2988

9. Nielsen MA, Staalsoe T, Kurtzhals JA, Goka BQ, Dodoo D, Alifrangis M, Theander TG, Akanmori BD, Hviid L: Plasmodium falciparum variant surface antigen expression varies between isolates causing severe and nonsevere malaria and is modified by acquired immunity. J Immunol 2002, 168:3444-3450.

10. Kraemer SM, Smith JD: A family affair: var genes, PfEMP1 binding, and malaria disease. Curr Opin Microbiol 2006, 9:374-380.

11. Roberts DJ, Pain A, Kai O, Kortok M, Marsh K: Autoagglutination of malaria-infected red blood cells and malaria severity. Lancet 2000, 355:1427-1428.

12. Normark J, Nilsson D, Ribacke U, Winter G, Moll K, Wheelock CE, Bayarugaba J, Kironde F, Egwang TG, Chen Q, Andersson B, Wahlgren M: PfEMP1-DBL1alpha amino acid motifs in severe disease states of Plasmodium falciparum malaria. Proc Natl Acad Sci USA 2007, 40:15835-15840

13. MacPherson GG, Warrell MJ, White NJ, Looareesuwan S, Warrell DA: Human cerebral malaria. A quantitative ultrastructural analysis of parasitized erythrocyte sequestration. Am J Pathol 1985, 119:385-401.

14. Flick K, Chen Q: var genes, PfEMP1 and the human host. Mol Biochem Parasitol 2004, 134:3-9.

15. Kraemer SM, Kyes SA, Aggarwal G, Springer AL, Nelson SO, Christodoulou Z, Smith LM, Wang W, Levin E, Newbold Cl, Myler PJ, Smith JD: Patterns of gene recombination shape var gene repertoires in Plasmodium falciparum: comparisons of geographically diverse isolates. $B M C$ Genomics 2007, 8:45.

16. Rowe JA, Moulds JM, Newbold Cl, Miller LH: P. falciparum rosetting mediated by a parasite-variant erythrocyte membrane protein and complement-receptor 1. Nature 1997, 388:292-295.

17. Chen Q, Heddini A, Barragan A, Fernandez V, Pearce SF, Wahlgren M: The semiconserved head structure of Plasmodium falciparum erythrocyte membrane protein 1 mediates binding to multiple independent host receptors. J Exp Med 2000, 192:1-10.

18. Vogt AM, Barragan A, Chen Q, Kironde F, Spillmann D, Wahlgren M: Heparan sulfate on endothelial cells mediates the binding of Plasmodium falciparum-infected erythrocytes via the DBL1alpha domain of PfEMP1. Blood 2003, 101:2405-2411, Epub 2002 Nov 2414
19. Chen Q, Pettersson F, Vogt AM, Schmidt B, Ahuja S, Liljestrom P, Wahlgren M: Immunization with PfEMP1-DBL1alpha generates antibodies that disrupt rosettes and protect against the sequestration of Plasmodium falciparum-infected erythrocytes. Vaccine 2004, 22:2701-2712.

20. Pettersson F, Vogt AM, Jonsson C, Mok BW, Shamaei-Tousi A, Bergstrom S, Chen Q, Wahlgren M: Whole-body imaging of sequestration of Plasmodium falciparum in the rat. Infect Immun 2005, 73:7736-7746.

21. Treutiger CJ, Hedlund I, Helmby H, Carlson J, Jepson A, Twumasi P, Kwiatkowski D, Greenwood BM, Wahlgren M: Rosette formation in Plasmodium falciparum isolates and anti-rosette activity of sera from Gambians with cerebral or uncomplicated malaria. Am J Trop Med Hyg 1992, 46:503-510.

22. Rowe A, Obeiro J, Newbold Cl, Marsh K: Plasmodium falciparum rosetting is associated with malaria severity in Kenya. Infect Immun 1995, 63:2323-2326.

23. Heddini A, Pettersson F, Kai O, Shafi J, Obiero J, Chen Q, Barragan A, Wahlgren M, Marsh K: Fresh isolates from children with severe Plasmodium falciparum malaria bind to multiple receptors. Infect Immun 2001, 69:5849-5856.

24. Pathirana SL, Alles HK, Bandara S, Phone-Kyaw M, Perera MK, Wickremasinghe AR, Mendis KN, Handunnetti SM: ABO-blood-group types and protection against severe, Plasmodium falciparum malaria. Ann Trop Med Parasitol 2005, 99:119-124.

25. Vigan-Womas I, Guillotte M, Le Scanf C, Igonet S, Petres S, Juillerat A, Badaut C, Nato F, Schneider A, Lavergne A, Contamin H, Tall A, Baril L, Bentley GA, Mercereau-Puijalon O: An in vivo and in vitro model of Plasmodium falciparum rosetting and autoagglutination mediated by varO, a group A var gene encoding a frequent serotype. Infect Immun 2008, 76:5565-5580.

26. Chen Q, Barragan A, Fernandez V, Sundstrom A, Schlichtherle M, Sahlen A, Carlson J, Datta S, Wahlgren M: Identification of Plasmodium falciparum erythrocyte membrane protein 1 (PfEMP1) as the rosetting ligand of the malaria parasite P. falciparum. J Exp Med 1998, 187:15-23.

27. Lavstsen T, Salanti A, Jensen AT, Arnot DE, Theander TG: Sub-grouping of Plasmodium falciparum 3D7 var genes based on sequence analysis of coding and non-coding regions. Malar J 2003, 2:27.

28. Bull PC, Berriman M, Kyes S, Quail MA, Hall N, Kortok MM, Marsh K, Newbold Cl: Plasmodium falciparum variant surface antigen expression patterns during malaria. PLoS Pathog 2005, 1:26.

29. Kaestli M, Cockburn IA, Cortes A, Baea K, Rowe JA, Beck HP: Virulence of malaria is associated with differential expression of Plasmodium falciparum var gene subgroups in a case-control study. J Infect Dis 2006, 193:1567-1574.

30. Rottmann M, Lavstsen T, Mugasa JP, Kaestli M, Jensen AT, Muller D, Theander T, Beck HP: Differential expression of var gene groups is associated with morbidity caused by Plasmodium falciparum infection in Tanzanian children. Infect Immun 2006, 74:3904-3911.

31. Su XZ, Heatwole VM, Wertheimer SP, Guinet F, Herrfeldt JA, Peterson DS, Ravetch JA, Wellems TE: The large diverse gene family var encodes proteins involved in cytoadherence and antigenic variation of Plasmodium falciparum-infected erythrocytes. Cell 1995, 82:89-100.

32. Blomqvist $K$, Normark J, Nilsson D, Ribacke U, Orikiriza J, Trillkott $P$, Byarugaba J, Egwang TG, Kironde F, Andersson B, Wahlgren M: var gene transcription dynamics in Plasmodium falciparum patient isolates. $\mathrm{Mol}$ Biochem Parasitol 2010, 170:74-83

33. Fernandez V, Treutiger CJ, Nash GB, Wahlgren M: Multiple adhesive phenotypes linked to rosetting binding of erythrocytes in Plasmodium falciparum malaria. Infect Immun 1998, 66:2969-2975.

34. Moll K, Ljungström I, H P, Scherf A, M W: Methods in Malaria Research, 5th ed. MR4/ATCC Manassas, Virginia. 2008 [http://www.biomalpar.org/ updatedMethods_In_Malaria_Research_5thedition.pdf].

35. Bustin SA, Benes V, Garson JA, Hellemans J, Huggett J, Kubista M, Mueller R, Nolan T, Pfaffl MW, Shipley GL, Vandesompele J, Wittwer CT: The MIQE guidelines: minimum information for publication of quantitative realtime PCR experiments. Clin Chem 2009, 55:611-622.

36. Moll K, Chene A, Ribacke U, Kaneko O, Nilsson S, Winter G, Haeggstrom M, Pan $W$, Berzins $K$, Wahlgren $M$, Chen $Q$ : A novel DBL-domain of the $P$. falciparum 332 molecule possibly involved in erythrocyte adhesion. PLOS One 2007, 2.

37. Haeggstrom M, Kironde F, Berzins K, Chen Q, Wahlgren M, Fernandez V: Common trafficking pathway for variant antigens destined for the 
surface of the Plasmodium falciparum-infected erythrocyte. Mol Biochem Parasitol 2004, 133:1-14.

38. Gardner MJ, Hall N, Fung E, White O, Berriman M, Hyman RW, Carlton JM, Pain A, Nelson KE, Bowman S, Paulsen IT, James K, Eisen JA, Rutherford K, Salzberg SL, Craig A, Kyes S, Chan MS, Nene V, Shallom SJ, Suh B, Peterson J, Angiuoli S, Pertea M, Allen J, Selengut J, Haft D, Mather MW, Vaidya AB, Martin DM, Fairlamb AH, Fraunholz MJ, Roos DS, Ralph SA, McFadden Gl, Cummings LM, Subramanian GM, Mungall C, Venter JC, Carucci DJ, Hoffman SL, Newbold C, Davis RW, Fraser CM, Barrell B: Genome sequence of the human malaria parasite Plasmodium falciparum. Nature 2002, 419:498-511.

39. Moll K, Pettersson F, Vogt AM, Jonsson C, Rasti N, Ahuja S, Spangberg M, Mercereau-Puijalon O, Arnot DE, Wahlgren M, Chen Q: Generation of crossprotective antibodies against Plasmodium falciparum sequestration by immunization with an erythrocyte membrane protein 1-duffy bindinglike 1 alpha domain. Infect Immun 2007, 75:211-219.

40. Kirchgatter K, del Portillo HA: Association of severe noncerebral Plasmodium falciparum malaria in Brazil with expressed PfEMP1 DBL1 alpha sequences lacking cysteine residues. Mol Med 2002, 8:16-23.

41. Warimwe GM, Keane TM, Fegan G, Musyoki JN, Newton CR, Pain A, Berriman M, Marsh K, Bull PC: Plasmodium falciparum var gene expression is modified by host immunity. Proc Natl Acad Sci USA 2009, 106:21801-21806.

42. Horrocks P, Pinches R, Kyes S, Kriek N, Lee S, Christodoulou Z, Newbold Cl Effect of var gene disruption on switching in Plasmodium falciparum. Mol Microbiol 2002, 45:1131-1141.

43. Taylor HM, Kyes SA, Harris D, Kriek N, Newbold Cl: A study of var gene transcription in vitro using universal var gene primers. Mol Biochem Parasitol 2000, 105:13-23.

44. Vogt AM, Pettersson F, Moll K, Jonsson C, Normark J, Ribacke U, Egwang TG, Ekre HP, Spillmann D, Chen Q, Wahlgren M: Release of sequestered malaria parasites upon injection of a glycosaminoglycan. PLoS Pathogens 2006, 2:100.

doi:10.1186/1475-2875-10-17

Cite this article as: Albrecht et al: var gene transcription and PfEMP1 expression in the rosetting and cytoadhesive Plasmodium falciparum clone FCR3S1.2. Malaria Journal 2011 10:17.

\section{Submit your next manuscript to BioMed Central and take full advantage of:}

- Convenient online submission

- Thorough peer review

- No space constraints or color figure charges

- Immediate publication on acceptance

- Inclusion in PubMed, CAS, Scopus and Google Scholar

- Research which is freely available for redistribution

Submit your manuscript at www.biomedcentral.com/submit 